\title{
Back Side Ablation of SiC Diodes using a q-switched NIR Laser
}

\author{
B. Adelmann*, A. Hürner**, G. L. Roth*, R. Hellmann* \\ *University of Applied Sciences Aschaffenburg, Würzburger Str. 45, 64743 Aschaffenburg, Germany \\ E-mail: Benedikt.adelmann@h-ab.de \\ ${ }^{* *}$ Chair of Electron Devices, University of Erlangen-Nuremberg, Schottkystrasse 10, 91058 Erlangen, Germany
}

\begin{abstract}
We study pulsed fiber laser back side ablation of silicon carbide diodes. With the objective to thin the $\mathrm{SiC}$ substrate thickness without damaging the semiconductor device or altering its electrical characteristics, we investigate the ablation characteristics of silicon carbide and determine the ablation threshold, rate and quality as well as the material composition at the ablated surface. Based on optimized process parameters, including track distance, laser repetition rate and scanning velocity, we micro structure the substrate of $\mathrm{SiC}$ diodes and compare its electrical characteristic to an unprocessed device. Our results prove that the typical diode characteristic and built-in voltage are not affected by the laser ablation process. Fiber laser back side ablation therefore offers a precise and efficient micro structuring approach for substrate thinning in silicon carbide technology.
\end{abstract}

DOI: $10.2961 / \mathrm{jlmn} .2015 .02 .0016$

Keywords: Laser ablation, fiber laser, $\mathrm{SiC}$ diode, serial resistance

\section{Introduction}

Silicon substrates form the fundamental basis of most semiconductor devices with all relevant technological process steps being well established. However, for new applications in high power electronics as well as for ultrafast electronic devices silicon has physical limitations. In contrast, silicon carbide ( $\mathrm{SiC})$ has distinct advantages over silicon. The most important advantages of $\mathrm{SiC}$ are i) the higher band gap of $3.2 \mathrm{eV}$ in $4 \mathrm{H}-\mathrm{SiC}$, ii) the thermal conductivity being twice as high as in silicon, iii) a ten times higher electrical disruptive strength and iv) the higher saturated electron drift velocity, which is twice as high as in silicon [1] [2].

In non-power electronic devices based on silicon substrates all electric contacts are, in general, located on the top side of the devices and the electrical current flows exclusively between these contacts within thin layers beneath the surface. Except from these thin layers on the top side, the volume of the substrate itself does not contribute to the electrical conduction. Opposite to this, in power electronics based on silicon as well as in silicon carbide based devices the electrical current flows from the top side to the bottom which necessitates electrical front- and backside contacts [3]. This architecture has the disadvantage of a long conducting path in the bulk material which results in an additional serial resistance. As the serial resistance increases with the substrate thickness, it is therefore highly desirable to reduce the substrate thickness.

However, due to the high chemical inertness of $\mathrm{SiC}$, common semiconductor micromachining techniques such as, e.g., etching with potassium hydroxide or ethylenediamine are inapplicable [4]. Possible wet etching methods for $\mathrm{SiC}$ require elevated temperatures as, e.g, phosphoric acid at $215^{\circ} \mathrm{C}$ or alkaline solutions of $\mathrm{K}_{3} \mathrm{Fe}(\mathrm{CN})_{6}$ at temperatures of higher than $100{ }^{\circ} \mathrm{C}$ [5]. As these conditions are unfavorable, the standard method for $\mathrm{SiC}$ micromachining is dry etching [6] [7]. The most common dry etching methods are $\mathrm{SF}_{6}$ with $\mathrm{O}_{2}, \mathrm{CF}_{4}$ optionally with $\mathrm{O}_{2}, \mathrm{Cl}_{2} \mathrm{Ar}$ or $\mathrm{Ar}$. The achieved etching rates are between $27 \mathrm{~nm} / \mathrm{min}$ and
$970 \mathrm{~nm} / \mathrm{min}$ [8] [9] [10]. Further etching methods are electrochemical etching [11] [12] and photo-electrochemical etching [13], which can achieve higher etching rates of $2 \mu \mathrm{m} / \mathrm{min}$.

Yet, these etching methods are disadvantageous as they require reticles and etch stops [4]. Especially for 3 dimensional structures requiring several etching steps, multiple reticles are needed. This, however, significantly increases processing costs. In contrast to etching, laser micro processing obviates any chemistry and offers a high degree of geometrical freedom without requiring mask techniques.

Laser ablation and drilling of $\mathrm{SiC}$ has been demonstrated using short and ultrashort pulsed lasers with pulse lengths in the nanosecond to femtosecond regime. Reitano et al. report an ablation threshold of $2 \mathrm{~J} / \mathrm{cm}^{2}$ for $6 \mathrm{H}-\mathrm{SiC}$ using a nanosecond $\mathrm{XeCl}$ excimer at $288 \mathrm{~nm}$ [14]. Between $3 \mathrm{~J} / \mathrm{cm}^{2}$ and $9 \mathrm{~J} / \mathrm{cm}^{2}$ an ablation of $55 \mathrm{~nm}$ per pulse was found. Gupta et al. also report the ablation threshold of $2 \mathrm{~J} / \mathrm{cm}^{2}$ employing a $248 \mathrm{~nm} \mathrm{KrF}$ Excimer laser [15]. Maximum ablation rates of $105 \mathrm{~nm}$ per pulse are found at $15 \mathrm{~J} / \mathrm{cm}^{2}$. In a comparative study is was shown that the ablation rate of $6 \mathrm{H}-\mathrm{SiC}$ is about $5 \mathrm{~nm}$ per pulse higher as compared to $4 \mathrm{H}-\mathrm{SiC}$.

In contrast to excimer lasers with high pulse energies in the range between $10 \mathrm{~mJ}$ and $300 \mathrm{~mJ}$ at low pulse repetition rates in the range of $10 \mathrm{~Hz}$ to $300 \mathrm{~Hz}$, frequency trippled Nd:YAG lasers provide higher repetition rates with lower pulse energies. Krueger et al. [16] [17] used a frequency tripled Nd:YAG laser at $355 \mathrm{~nm}$ with $73 \mathrm{~J} / \mathrm{cm}^{2}$ fluence $(65 \mu \mathrm{J}$ on $15 \mu \mathrm{m}$ diameter $)$ and a repetition rate of $10 \mathrm{kHz}$ to ablate blind vias in SiC. For $380 \mu \mathrm{m}$ deep holes with $75 \mu \mathrm{m}$ diameter 2 seconds are required. To form a flat bottom of the blind holes, after the laser process IPC etching was applied.

To reduce the thermal energy deposited into the material Molian et al. used a 2 ps ultrashort pulsed laser with $1552 \mathrm{~nm}$ wavelength and $5 \mu \mathrm{J}$ pulse energy to ablate $4 \mathrm{H}-$ $\mathrm{SiC}$ [18]. Using such ultrashort pulsed laser, it was possible to ablate a $26 \mu \mathrm{m}$ deep cavity with sharp edges, no cracks 
and no melt formation. The maximum ablation rate is determined to be $18 \mathrm{~nm}$ per pulse at $10 \mathrm{~J} / \mathrm{cm}^{2}$. For using a $1028 \mathrm{~nm}$ Ti-Sapphire laser with a pulse duration of $200 \mathrm{fs}$, Farsari et al. calculated the dimension of the laser induced heat affected zone in $\mathrm{SiC}$ to $3.6 \mu \mathrm{m}$ [19] [20].

Though it has been demonstrated that laser ablation of SiC semiconductors is possible with UV and ultrashort pulsed lasers, as summarized above, the influence of such ablation processes on the function of semiconductor devices is so far not addressed in literature. Taken into account the device architecture, which encompasses the device beneath the front side contact on the underlying substrate (cf. figure 1), it has to be considered that during substrate ablation from the back side laser radiation will also penetrate the device region. The amount of laser energy reaching the electrical device depends on the absorption which in turn depends on laser wavelength. As a matter of course, any adverse effects or damage of the device during laser ablation has to be avoided. In this contribution we therefore investigate the influence of back side substrate ablation on the function of a $\mathrm{SiC}$ diode.

\section{Experimental}

\subsection{SiC Diodes}

The schematic cross section of the SiC diode chosen for the experimental study of laser ablation is depicted in figure 1. The diode is grown on a $5 \times 10^{18} 1 / \mathrm{cm}^{3} \mathrm{n}$-doped $4-\mathrm{H}$ silicon carbide substrate with a thickness of $400 \mu \mathrm{m}$, on which a typical backside metallization stack is deposited. On the front side, a $10 \mu \mathrm{m}$ epitaxial layer of p-doped $\mathrm{SiC}$ with an acceptor concentration of approximately $10^{15} 1 / \mathrm{cm}^{3}$ is grown, forming the diode. An additional $800 \mathrm{~nm}$ deep pdoped zone with a carrier concentration of $10^{19} 1 / \mathrm{cm}^{3}$ is implanted into the front side $\mathrm{p}$-SiC epitaxial layer to achieve an electrical contact to the metal layer above. The electrical front contact is subsequently completed by a $100 \mathrm{~nm}$ thin titanium layer followed by a $4 \mu \mathrm{m}$ thick aluminum layer.

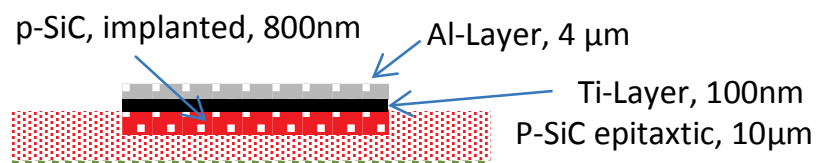

Ni-Layer, $100 \mathrm{~nm}$ n-type SiC substrate

Laser ablated area $\times$ Al-Layer, $4 \mu \mathrm{m}$

Figure 1: Architecture of the laser processed $\mathrm{SiC}$ diode

Laser ablation is carried out from the back side to reduce the thickness of the SiC n-type substrate. After ablation a $100 \mathrm{~nm}$ thin nickel layer is sputtered on the ablated area to renew the electrical back side contact and to facilitate electrical measurements of the diode characteristics.
At the laser wavelength employed in this study $(1070 \mathrm{~nm})$, we determined the optical transmission of the substrate to $44 \%$ and the reflection to $32 \%$. The resulting absorption of $24 \%$ corresponds to an absorption coefficient of $1062 \mathrm{~m}^{-1}$ and a penetration depth of $940 \mu \mathrm{m}$. Please note that these measurements were conducted at room temperature. These optical properties, however, may significantly alter at high temperatures which occur during laser processing. Nonetheless, the high transmission indicates the possibility to affect the active device on the front side during laser ablation.

\subsection{Laser system}

For the experiments a pulsed (Q-switched) $20 \mathrm{~W}$ fiber laser is used (YLP Series, IPG Photonics). The laser is specified by an emission wavelength of $1070 \mathrm{~nm}$, a pulse length of $100 \mathrm{~ns}$, and a beam quality of $\mathrm{M}^{2}=1.6$. The repetition rate can be adjusted between $2 \mathrm{kHz}$ and $80 \mathrm{kHz}$ with the average power of $20 \mathrm{~W}$ being available at $20 \mathrm{kHz}$. The maximum pulse energy is $1 \mathrm{~mJ}$ and the maximum fluence is $128 \mathrm{~J} / \mathrm{cm}^{2}$ for a $45 \mu \mathrm{m}$ spot diameter. At repetition rates below $20 \mathrm{kHz}$ the average power decreases at constant pulse energy. Above $20 \mathrm{kHz}$ the average power remains constant with a decreasing the pulse energy. The output power can get adjusted between $10 \%$ and $100 \%$ of the nominal power of $20 \mathrm{~W}$.

The laser beam is positioned by a galvanometer (Raylase SuperScan) with $163 \mathrm{~mm}$ focal length. This scanner has a maximum positioning speed of $>7 \mathrm{~m} / \mathrm{s}$ deflected over a range of $110 \times 110 \mathrm{~mm}^{2}$.

\section{Results and Discussion}

\subsection{Laser ablation characteristics of $\mathrm{SiC}$}

To facilitate a controlled back side laser ablation of the $\mathrm{SiC}$ substrate, fundamental ablation characteristics, such as ablation threshold, rate and quality as well as the material composition at the ablated surface, have to be initially determined. For the material under study, we have measured an ablation threshold of $30 \mathrm{~J} / \mathrm{cm}^{2}$ for 100 pulses according the most commonly used procedure by Liu et al. [21]. This is considerable higher as compared to thresholds reported for ablation using UV excimer or picosecond lasers [14] [15] [18], which is attributed to the lower IR absorption of the fiber laser and its longer pulse length. Nevertheless, the concession of a higher ablation threshold is associated with a significantly simpler and cost efficient fiber laser system.

To reduce the $\mathrm{SiC}$ substrate thickness, a larger area with defined depth has to be ablated in a multi pass, meander type scan. To optimize such a scan strategy, we have investigated the influence of track distance, pulse repetition rate, and scan velocity (both define the pulse overlap) on the ablation rate, surface roughness, edge steepness and chipping of the semiconductor material. Since this contribution focusses on the function of the $\mathrm{SiC}$ diode after back side laser ablation, here we only briefly summarize the results of this optimization. As a consequence, the track distance of the meander type scan path is chosen to $36 \mu \mathrm{m}$ (laser spot diameter is $45 \mu \mathrm{m})$. A lower track distance leads to a higher surface roughness and a higher track distance results in an incomplete ablation. The pulse repetition rate is set to 
$2 \mathrm{kHz}$ (minimum of the laser system) with higher repetition rates resulting in a higher roughness and lower edge steepness. Finally, a scanning velocity of $20 \mathrm{~mm} / \mathrm{s}$ is used as higher velocities lead to chipping of the material next to the ablated area. In turn, lower scanning velocities result in a higher surface roughness of the ablated area. Employing this parameter combination (track distance $36 \mu \mathrm{m}, 2 \mathrm{kHz}$ repetition rate and $20 \mathrm{~mm} / \mathrm{s}$ ) as a trade of between low surface roughness, avoidance of chipping and high process speed, the ablation rate is determined to $0.58 \mathrm{~mm}^{3} / \mathrm{min}$, which is notably higher as compared to the rate of $0.0018 \mathrm{~mm}^{3} / \mathrm{min}$ reported for a frequency tripled $\mathrm{Nd}$ :YAG laser by Kreutz et al. [22].

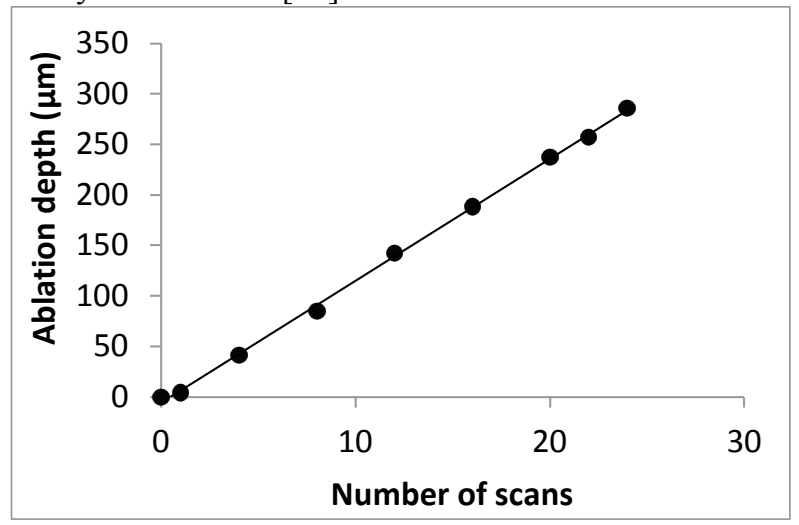

Figure 2: Ablation depth as a function of the number of scans (repetition rate $2 \mathrm{kHz}$ and scanning speed $20 \mathrm{~mm} / \mathrm{s}$ )

To achieve a defined ablation depth, multiple scans are necessary. Figure 2 shows the ablation depth as a function of the number of scans. Apparently, the ablation depth increases linearly with the number of scans with $12 \mu \mathrm{m}$ per scan. This linear dependence allows to easily control the ablation depth by adjusting the number of scans. To evaluate the accuracy of this multi pass ablation process we processed multiple specimens and determined the standard error of the achieved ablation depth. We found standard errors of $0.8 \mu \mathrm{m}(0.7 \%)$ for an ablation depth of $110 \mu \mathrm{m}$ and $1.2 \mu \mathrm{m}(0.4 \%)$ for $310 \mu \mathrm{m}$ ablation depth, highlighting the high accuracy of the process.

With respect to any subsequent processing of the semiconductor device, e.g. metal deposition or etching, the surface roughness after laser ablation is of importance. We therefore have measured the surface roughness $(\mathrm{Ra})$ of the ablated area using a laser scanning microscope. Figure 3 depicts the roughness as a function of the ablation depth. Starting from $\mathrm{Ra}=1 \mu \mathrm{m}$ for the untreated surface, laser ablation roughens the surface with $\mathrm{Ra}$ depending linearly on the ablation depth. Please note that for these experiments the optimized laser parameters described above have been used (track distance $36 \mu \mathrm{m}$, pulse repetition rate $2 \mathrm{kHz}$ and scan speed $20 \mathrm{~mm} / \mathrm{s}$ ).

Besides the surface roughness, for subsequent processes the material composition on the ablated surface is also of importance, e.g. for electrical contact generation by metallization [23]. We, therefore, have determined the composition by means of an EDX analysis prior and after laser ablation.
In course of the laser ablation, a white powder is observable on the treated surface, which is easily removable in an ultrasonic bath. This is identified as $\mathrm{SiO}_{2}$, with the EDX analysis determining oxygen in the range of 23 at \%. This white powder was also reported by Kreutz et al. [22] with an oxygen content of 18 at $\%$.

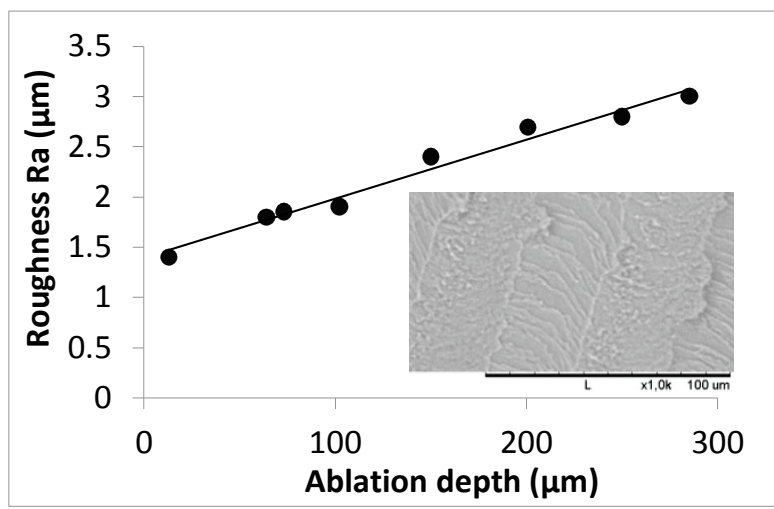

Figure 3: Surface roughness $(\mathrm{Ra})$ as a function of the ablation depth. The inset depicts a SEM image of the laser ablated area, in which the adjacent ablation tracks can be seen.

After back side ablation of $100 \mu \mathrm{m}$ (i.e. the $4 \mu \mathrm{m}$ aluminum layer and $96 \mu \mathrm{m} \mathrm{SiC} \mathrm{are} \mathrm{removed,} \mathrm{cf.} \mathrm{figure} \mathrm{1)} \mathrm{and}$ ultrasonic cleaning we find that the composition of the $\mathrm{SiC}$ substrate on the surface is altered. In particular, the amount of silicon is reduced as compared to untreated regions by a few percent, while the amount of carbon is correspondingly increased and an additional 2 at \% aluminum is found. We attribute both the reduced silicon and increased carbon portion to the laser induced ejection of liquid silicon. According to Samant et al. [24], the latter is formed by a decomposition of $\mathrm{SiC}$ into solid carbon and liquid silicon at elevated temperatures during the ablation process. As the silicon is ejected, the proportional composition at the surface is shifted in favor of carbon.

\subsection{Electrical characteristics of back side ablated SiC diodes}

Based on these laser ablation characteristics, $\mathrm{SiC}$ diodes are back side ablated to reduce the thickness of the SiC substrate. To verify that after laser ablation the function of the semiconductor diode is not negatively affected, we structured $2 \times 2 \mathrm{~mm}^{2}$ wells with different depths $(200 \mu \mathrm{m}$, $301 \mu \mathrm{m}$, and $329 \mu \mathrm{m}$ ) into the substrate. According to figure 2 , the ablation depth is controlled by the number of meander type scans with the process parameters being track spacing of $36 \mu \mathrm{m}$, pulse repetition rate $2 \mathrm{kHz}$, and scanning speed $20 \mathrm{~mm} / \mathrm{s}$, respectively. As for the meander type scan the edges of the well experience a longer laser exposure during the inversion of the scanning direction, an additional deepening in excess of the ablated layer is observed. In this respect, it is worthwhile to mention that for a well of $329 \mu \mathrm{m}$ depths only a thin substrate layer of about $70 \mu \mathrm{m}$ remains, which is associated by the risk of mechanical breakup. In case of the $329 \mu \mathrm{m}$ well, we therefore cascaded the well structure by two additional steps. Figure 4 shows this cascaded well structure as measured by a laser scan- 
ning microscope, revealing the high quality and accuracy of the laser micro structuring process. Table 1 summarizes the processing time and measured roughness of the three wells generated in $\mathrm{SiC}$.

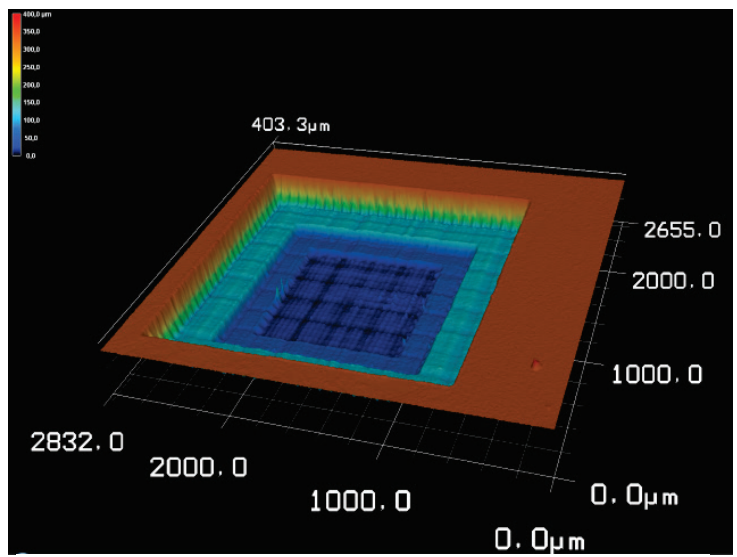

Figure 4: Laser scanning image of a $329 \mu \mathrm{m}$ deep groove with 3 cascaded steps

After back side laser ablation the diodes are cleaned for 5 minutes in an ultrasonic bath to remove any debris. Afterwards a $100 \mathrm{~nm}$ nickel layer is sputtered onto the ablated area to form the new back side electrical contact. The electrical characteristics of the diode are determined by measuring the diode current as a function of voltage. Figure 5 compares this diode characteristic for an unprocessed reference device and the laser processed specimen. The reference diode is characterized by a reverse current of $0.1 \mu \mathrm{A}$ at $5 \mathrm{~V}$ and a built-in voltage of $2.5 \mathrm{~V}$.

Table 1: Depth, roughness and processing time of back side ablated $\mathrm{SiC}$ diodes

\begin{tabular}{|c|c|c|}
\hline Depth $(\mu \mathrm{m})$ & $\begin{array}{l}\text { Roughness Ra } \\
(\mu \mathrm{m})\end{array}$ & Processing Time (s) \\
\hline $200( \pm 0.8)$ & 3.3 & 124.2 \\
\hline $301( \pm 1)$ & 3.4 & 151.4 \\
\hline 329 & 3.8 & 158.3 \\
\hline
\end{tabular}

The results depicted in figure 5 highlight that the typical diode characteristic of an exponential dependence between diode current and applied voltage is not affected by the laser ablation process, i.e. the semiconductor diode is neither damaged nor negatively influenced. In addition, the built-in voltage remains unchanged at $2.5 \mathrm{~V}$ and in reverse direction of up to $-5 \mathrm{~V}$ no significant change is ascertained (the reverse current at $5 \mathrm{~V}$ is slightly reduced on the order of $0.06 \mu \mathrm{A}$, which is not resolved on the current scale in the figure 5).

For voltages above the built-in voltage the diode current is considerably reduced as compared to the reference diode, indicating an increasing forward voltage. However, as the experimental results in figure 5 show, this reduction does not unambiguously scale with the ablation depth. Hence, we conclude that the contact resistance between $\mathrm{SiC}$ and nickel dominates the measured resistance rather than the path resistance of the remaining $\mathrm{SiC}$ substrate. The contact resistance can be estimated by the additional voltage drop of a processed diode as compared to the reference diode at constant current. For instance, at a current of $100 \mathrm{~mA}$ in the reference specimen a voltage drop of $3 \mathrm{~V}$ is observed and for the $200 \mu \mathrm{m}$ ablated sample the voltage drop is measured to about $5 \mathrm{~V}$ (cf. figure 5). From this voltage difference of $2 \mathrm{~V}$ at $100 \mathrm{~mA}$ which drops at the back side contact the contact resistance is estimated to be

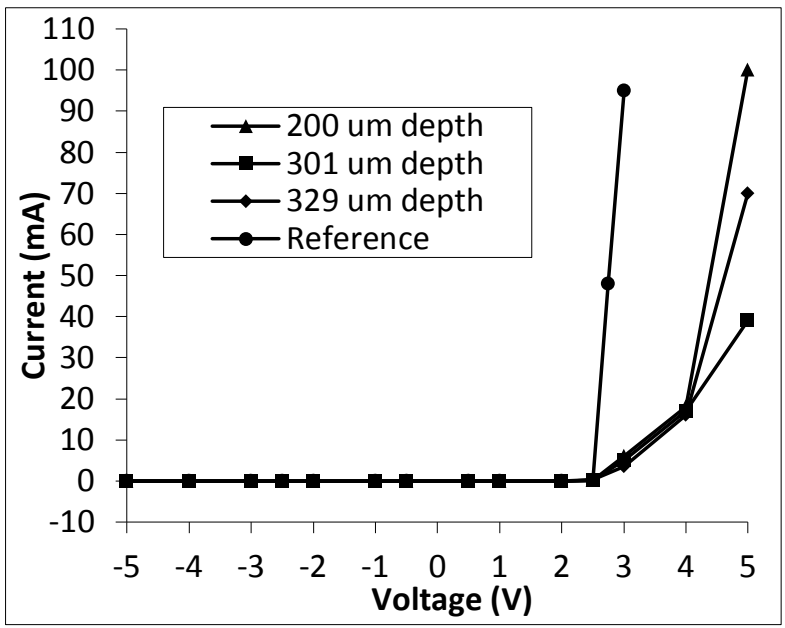

Figure 5: Current over voltage characteristic of the reference diode and the laser structured diodes.

about $20 \Omega$ which is not unusual for a barely optimized metal $\mathrm{SiC}$ contact [23]. Nonetheless, these results clearly demonstrate that laser ablation can be employed to structure $\mathrm{SiC}$ diodes under perpetuation of the device characteristics. This in turn offers an innovative approach to thin $\mathrm{SiC}$ devices.

\section{Conclusion}

We have demonstrated that laser ablation using pulsed fiber laser can be employed to thin silicon carbide substrates beneath a functional diode without damaging the semiconductor device or altering its electrical characteristics. Especially, the built-in voltage and the typical currentvoltage characteristics are unaffected by the laser process.

To enable high quality back side laser ablation of the $\mathrm{SiC}$ substrates, the ablation characteristics, such as ablation threshold, ablation rate and surface quality have been determined to identify an optimized parameter range for the ablation. In particular, the ablation rate is found to be $0.58 \mathrm{~mm}^{3} / \mathrm{min}$ allowing an efficient, high quality and precise ablation process.

\section{References}

[1] T. Mnatsakanov, L. Pomortseva and S. Yurkov, "Semiempirical model of carrier mobility in silicon carbide for analyzing its dependence on temperature and doping level," Physics and Astronomy, pp. 394397, 4352001.

[2] M. Ostling, "High power devices in wide bandgap semiconductors," Science China, p. 1087-1093, 5 2011.

[3] T. Chow, N. Ramungul, J. Fedison and Y. Tang, "SiC Power Bipolar Transistors and Thyristors," in Silicon Carbide, Berlin, Springer, 2003, pp. 737-764. 
[4] C. A. Zormann and M. Mehregany, "Micromachining of SiC," in Silicon Carbide, Berlin, Springer, 2004, pp. 671-698.

[5] D. Zhuang and J. J. Edgar, "Wet etching of GaN, AlN, and SiC: a review," Materials Science and Engineering, pp. 1-46, 48 R 2005.

[6] H. Cho, P. Leerungnawarat, D. C. Hays, S. Pearton, S. Chu, R. Strong, C. Zetterling, M. Ostling and F. Ren, "Ultradeep, low-damage dry etching of SiC," Applied Physics Letters, pp. 739-741, 6762000.

[7] L. Jiang, R. Cheung, M. Hassan, A. Harris, J. Burdess, C. Zorman and M. Mehregany, "Fabrication of SiC microelectromechanical systems using one-step dry etching," Journal of Vacuum Science \& Technology B, pp. 2998-3001, 6212003.

[8] J. Sugiura, W. Lu, K. Cadien and A. Steckl, "Reactive ion etching of SiC thin films using fluorinated gases," Journal of Vacuum Science \& Technology B, pp. 349354, 141986.

[9] L. Jiang, N. Plank, M. Blauw, R. Cheung and E. Drift, "Dry etching of $\mathrm{SiC}$ in inductively coupled $\mathrm{Cl} 2 / \mathrm{Ar}$ plasma," Journal of Physics D: Applied Physics, p. 1809, 13372004.

[10] F. Khan and I. Adesida, "High rate etching of SiC using inductively coupled plasma reactive ion etching in SF 6-based gas mixtures," Applied physics letters, pp. 2268-2270, 15751999.

[11] V. Petrova-Koch, O. Sreseli, G. Polisski, D. Kovalev, T. Mischik and F. Koch, "Luminescence enhancement by electrochemical etching of $\mathrm{SiC}(6 \mathrm{H})$," Thin Solid Films, pp. 107-110, 12551995.

[12] S. Rysy, H. Sadovski and R. Helbig, "Electrochemical etching of silicon carbide," Journal of Solid State Electrochemistry, pp. 437-445, 7-8 31999.

[13] J. Shor and A. Kurtz, "Photoelectrochemical Etching of $6 \mathrm{H}-\mathrm{SiC}, "$ Journal of the Electrochemical Society, pp. 778-781, 31411994.

[14] R. Reitano, P. Baeri and N. Marino, "Excimer laser induced thermal evaporation and ablation of silicon carbide," Applied surface science, pp. 302-308, 96 1996.

[15] S. Gupta, B. Pecholt and P. Molian, "Excimer laser ablation of single crystal $4 \mathrm{H}-\mathrm{SiC}$ and $6 \mathrm{H}-\mathrm{SiC}$ wafers," Journal of Materials Science, pp. 196-206, 462011.

[16] O. Krueger, G. Schoene, T. Wernicke, W. John, J. Wurfl and G. Traenkle, "UV laser drilling of SiC for semiconductor device fabrication," Journal of Physics, pp. 740-744, 592007.

[17] O. Krueger and R. Grundmueller, "UV Laser Processing for Semiconductor Devices," Laser Technik Journal, pp. 26-30, 102013.

[18] P. Molian, B. Pecholt and S. Gupta, "Picosecond pulsed laser ablation and micromachining of $4 \mathrm{H}-\mathrm{SiC}$ wafers," Applied Surface Science, pp. 4515-4520, 255 2009.

[19] M. Farsari, G. Filippidis, S. Zoppel, G. Reider and C. Fotakis, "Efficient Femtosecond lasesr micromachining of bulk 3C-SiC," Journal of Micromechanics and Microengineering, pp. 17861789, 152005.

[20] M. Farsari, G. Filippidis, S. Zoppel, G. Reider and C. Fotakis, "Micromachining of Silicon Carbide using femtosecond lasers," Journal of Physics: Conference Series, p. 84-87, 592007.

[21] J. M. Liu, "Simple technique for measurements of pulsed Gaussian-beam spot sizes," Optics Letters, vol. 7, no. 5, pp. 196-198, May 1982.

[22] E. Kreutz, R. Weichenhain, A. Horn and R. Poprawe, "Manufacturing of Precise SiC Components by Nd: YAG Laser Radiation," Solid State Phenomena, pp. 441-446, 802001.

[23] B. Adelmann, A. Hürner, T. Schlegel, A. J. Bauer, L. Frey and R. Hellmann, "Laser Alloying Nickel on 4HSilicon Carbide Substrate to Generate Ohmic Contacts," Journal of Laser Micro/Nanoengineering, Vols. 8-1, pp. 97-101, 2013.

[24] A. Samant, C. Daniel, R. Chand, C. Blue and N. Dahotre, "Computational approach to photonic drilling of silicon carbide," The International Journal of Advanced Manufacturing Technology, pp. 704-713, 45 2009.

[25] S. Baudach, J. Bonse and W. Kautek, "Ablation experiments on polyimide with femtosecond laser pulses," Applied Physics A, pp. 395-398, 691999.

[26] J. Bonse, J. Wrobel, J. Krueger and W. Kautek, "Ultrashort-pulse laser ablation of indium phosphide in air," Applied Physics A, pp. 89-94, 722001.

[27] W. Shi, Y. Zheng, H. Peng, N. Wang, C. Lee and S. Lee, "Laser ablation synthesis and optical characterization of silicon carbide nanowires," Journal of the American Ceramic Society, pp. 3228-3230, 83 2000.

[28] U. Engelhardt, J. Hildenhagen and K. Dickmann, "Micromachining using high-power picosecond lasers," Laser Technik Journal, vol. 8, no. 5, pp. 3235, 2011.

(Received: October 31, 2015, Accepted: March 22, 2015) 